This item was submitted to Loughborough's Research Repository by the author.

Items in Figshare are protected by copyright, with all rights reserved, unless otherwise indicated.

\title{
Effects of teamwork climate on cooperation in crossfunctional temporary multi-organization workgroups
}

\section{PLEASE CITE THE PUBLISHED VERSION}

http://dx.doi.org/10.1061/(ASCE)CO.1943-7862.0001029

\section{PUBLISHER}

(c) American Society of Civil Engineers

\section{VERSION}

AM (Accepted Manuscript)

\section{PUBLISHER STATEMENT}

This work is made available according to the conditions of the Creative Commons Attribution-NonCommercialNoDerivatives 4.0 International (CC BY-NC-ND 4.0) licence. Full details of this licence are available at: https://creativecommons.org/licenses/by-nc-nd/4.0/

\section{LICENCE}

CC BY-NC-ND 4.0

\section{REPOSITORY RECORD}

Anvuur, Aaron, and Mohan M. Kumaraswamy. 2015. "Effects of Teamwork Climate on Cooperation in Crossfunctional Temporary Multi-organization Workgroups". Loughborough University. https://hdl.handle.net/2134/18078. 


\title{
Effects of teamwork climate on cooperation in cross-functional
}

2

\section{Abstract}

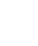

\section{temporary multi-organization workgroups}

\author{
Aaron M. Anvuur, Ph.D. ${ }^{1}$; and Mohan M. Kumaraswamy, Ph.D., M.ASCE²
}

In this study, the formative roles of common goals, equal status, integrative interactions, and authority support as the optimal factors for engendering individuals' cooperation with their proximal cross-functional project workgroups are examined. The four factors are properties of the workgroup environment, and have each been highlighted as being important in previous conceptual and critical success factors (CSFs) studies of project effectiveness. However, until now, there has been no systematic empirical test of the interactive effects of all four factors in a construction temporary-multiorganization (TMO) workgroup setting. The four factors are conceptualized in this study as the reflective dimensions of a superordinate multidimensional latent construct, teamwork climate. An integrative test was undertaken of the construct validity of this multidimensional construct, its substantive utility relative to its dimensions, and of specific hypotheses connecting the multidimensional construct and its dimensions to individual's in-role, extra-role, compliance, and deference behaviour; the test was performed using two cross-cultural samples of built environment professional managers (UK, $N=381$; and Hong Kong, $N=140$ ) and structural equation modelling. The

\footnotetext{
${ }^{1}$ Senior Lecturer, School of Civil and Building Engineering, Loughborough University, Ashby Road,
} Loughborough, LE11 3TU, UK (corresponding author). ORCID ID: 0000-0002-6863-2018. Email:

A.M.Anvuur@lboro.ac.uk

${ }^{2}$ Honorary Professor, Department of Civil Engineering, The University of Hong Kong, Pokfulam Rd., Hong Kong. ORCID ID: 0000-0003-1127-5141. E-mail: mohan@hku.hk 
results showed convergence in support of the multidimensional conceptualization of teamwork

climate, and also show that teamwork climate significantly and positively influences workgroup

members' in-role, extra-role, compliance, and deference behavior. These findings provide compelling indication that teamwork climate is an important and efficient determinant of cooperative behavior within TMO contexts and, in so doing, make an important contribution to the extant and construction engineering and management lines of literature on work climates. This study also makes an important contribution to the debate in the extant literature about how to model the four climate dimensions, in so far as it shows that a superordinate multidimensional conceptualization maximizes predictive utility, theoretical parsimony and bandwidth. Finally, this study makes an important contribution to practice, as it focuses project managers' attention on creating the generative project environments for the four optimal conditions for teamwork.

Keywords: Alignment, Cooperation, Cross-Functional Workgroup, Teamwork Climate,

Temporary Multi-Organization (TMO).

\section{Introduction} complementary functional specialisms that tend to be across - rather than within - firms and have high interdependencies in inputs, processes and outcomes (Hobday, 1998). Workgroup members in such temporary multi-organizations (TMOs) as coalitions are, thus, boundary spanners. The managerial imperative for joint-production in construction TMOs becomes, essentially, one of crossfunctional integration (Lawrence and Lorsch, 1967). This shift in emphasis from (the management of) task execution (taskwork) and towards issues of coordination and cooperation (teamwork) is an enduring challenge for construction projects. Teamwork has been defined conceptually as "a set of interrelated cognitions, attitudes, and behaviors contributing to the dynamic processes of 
performance" (Salas et al., 2008:541). Performance here refers to the actual activity engaged in (the behaviour) that advances the goals of the social collective - not an appraisal of the outcomes of that activity, which is effectiveness (Dulaimi and Langford, 1999; Salas et al., 2008). The question of how to foster effective teamwork in joint-production environments has attracted, and continues to attract, a lot of attention from researchers. One of the key discoveries of previous research in this area is that favourable (shared) cognitions about the work environment and its expected behaviour can promote effective teamwork and cooperation (DeChurch and Mesmer-Magnus, 2010; Mohammed et al., 2010). Previous research also highlights the crucial role of training, coaching and facilitation (i.e. teambuilding activities) in creating and sustaining favourable group cognitions (Salas et al., 2008).

In the context of construction projects, efforts at promoting effective teamwork mainly take the form of interventions for socialization, and focus on the creation of conducive work environments. Such efforts are broadly represented by the partnering ethos (Anvuur and Kumaraswamy, 2007). Based on an extensive analysis and synthesis of the extant literature, Anvuur and Kumaraswamy (2007) developed a conceptual model for partnering and alliancing. The model emphasizes the formative role of four factors in promoting effective teamwork in TMO workgroups: common goals, equal status, integrative interactions, and authority support. The four factors (explained later) are properties of the TMO workgroup environment. They are distinct yet highly interrelated and mutually reinforcing concepts; thereby representing a superordinate multidimensional latent construct (Law et al., 1998), referred to this study as teamwork climate. Our labeling of this superordinate multidimensional construct as teamwork climate is consistent with the enduring definition of climate as perceptions of the policies, practices and procedures that a social collective rewards, supports, and expects (cf. Schneider and Reichers, 1983; Kuenzi and Schminke, 2009). We

63 focus here on TMO workgroup members' individual perceptions of their workgroup environment - 
i.e. psychological climate - rather than their shared perceptions of the TMO workgroup environment

65

66

(i.e. workgroup climate), not least because the latter ultimately emanates from the former (cf.

Schneider and Reichers, 1983; Mathisen et al., 2006; Kuenzi and Schminke, 2009). Thus, with this definition of climate, a distinction is drawn between teamwork climate and with culture, which pertains to deep-seated and enduring manifestations of the worldview and values of a social collective, usually through its forms (e.g. artifacts, legends and symbols) (Fellows and Liu, 2013; Schneider et al., 2013). Indeed, in the context of TMO project settings, it has been argued that application of the notion 'project culture' to most projects (except perhaps some mega-projects) is misleading (Fellows and Liu, 2013: 4).

The notion that the workgroup environment influences teamwork in construction TMO settings is not new. Indeed, the importance of the TMO workgroup environment has been highlighted in numerous conceptual and critical success factors (CSFs) studies of project effectiveness (cf. Anvuur and Kumaraswamy, 2007). Construction management research studies have also reported significant teamwork consequences of one or another of the teamwork climate dimensions (e.g. Brookes et al., 2006; Tuuli and Rowlinson, 2009). However, there is as yet no systematic empirical test of the interactive effects of all four teamwork climate dimensions in a construction TMO workgroup setting. The purpose of this paper is to redress this by empirically testing the effects of the multidimensional teamwork climate construct on the cooperation of project actors with their TMO workgroups. If support were to be found for the hypotheses put forth in this paper linking teamwork climate to individuals' cooperation, this would also constitute a needful and substantive validation of the conceptual framework developed by Anvuur and Kumaraswamy (2007). In the sections that follow, a brief description of the conceptual model developed by Anvuur and Kumaraswamy (2007) is presented, along with the study hypotheses. Next, the data collection and analysis methods are 
described. We then present the results of the data analyses and discuss the implications of our findings for research and practice.

\section{Conceptual model}

The framework developed by Anvuur and Kumaraswamy (2007) is as shown in Fig. 1, except

for clarity and consistency in terminology, "cooperative interactions" has been replaced with

"integrative interactions". The dominant construction industry conditions that were the original

drivers for the partnering motif and still persist to this date, are depicted in the left-hand column of

Fig. 1. The four teamwork climate dimensions in column 3 (third from left) are process benefits from the implementation of the key components of partnering in column 2. The first teamwork climate dimension, equal status, underscores the presence of a workgroup environment characterized by

mutual professional respect for members' work inputs. The second dimension, integrative

interactions, reflects the extent to which workgroup interactions are inclusive, constructive and take

place in a positive and non-threatening environment. The third dimension of the teamwork climate

construct, common goals, underscores the presence and salience of a normative goal frame that

101

motivates workgroup members to enact such behaviors as are necessary to advance the goals of the workgroup. The final dimension, authority support, underscores the presence and abundance of senior management support for collaborative working; this implies both articulated support (e.g. in a project charter and use of underlying contracts - or relevant amendments to conditions of contract that are supportive of the development of relational norms) and enacted support (e.g. budget allocation and authority to 'do deals' independent of direct functional interference). These teamwork climate dimensions, acting in concert, lead to the content benefits of partnering (e.g. cooperation, project effectiveness, innovation) in the right-hand column of Fig. 1. Note also that many other cognitive and affective processes mediate the effects of the content benefits (e.g. interpersonal trust, positive affect, 
group identification). Thus, teamwork climate is conceptualized here to be associated with global

111 individual, collective and project level outcomes.

The four teamwork climate dimensions are interrelated and reinforcing; they are

conceptualized as reflective dimensions of a superordinate multidimensional (teamwork climate)

construct. For example, authority support, when present, helps to stabilize the normative goal (i.e.

common goal) frame in workgroup members through "goal contagion" effects and when absent, can

create subversive undercurrents to any shared cognition developed by workgroup members

(Lindenberg and Foss, 2011). Integrative interactions, when experienced by individuals in workgroup

settings, create feelings of professional respect, self-worth and equal status to significant others. A

detailed explication of the theoretical antecedents of the four teamwork climate dimensions and their

conceptual and practical relevance to construction TMOs is provided in Anvuur and Kumaraswamy

(2007); however, a brief description is presented below.

The four teamwork climate dimensions were proposed by Allport (1954) in what is known as

the "contact hypothesis", as the optimal conditions for reducing prejudice in intergroup interactions.

Allport's (1954) formulation of the contact hypothesis formed the foundations of a strong and

established research tradition on intergroup contact theory, involving field, experimental, archival,

racial and ethnic targets while later research extended the focus to also include a diverse range of targets like the elderly, disabled people, and employees of companies that have undergone a merger or acquisition (cf. Gaertner and Dovidio, 2000). Pettigrew and Tropp (2006) performed a meta-analytic test of intergroup contact theory using 713 independent samples from 515 studies. Their findings 
show that contact effects generalize to the entire outgroup and across contact settings. Pettigrew and

134 Tropp (2006) concluded that intergroup contact theory should be extended to other groups as well, as

135 a general social psychology theory. Further, upon closer examination of their results, Pettigrew and

136 Tropp (2006) concluded that the four optimal conditions are "best conceptualized as an interrelated

137 bundle rather than as independent factors" (p.751).

Within the work climate literature, West (1990; West and Anderson, 1996) proposed a climate

for workgroup innovation model consisting of four factors, similar to the contact factors: clarity of and commitment to objectives ('vision'); participation; task orientation; and support for innovation. West and Anderson's (1996) task orientation factor is based on Tjosvold et al.'s (1986: 127) notion of constructive controversy: frank and open-minded exploration of all views on a group decision problem, and their integration into high quality final solutions. Anderson and West (1998) developed and validated the climate for workgroup innovation model in the Team Climate Inventory (TCI).

Anderson and West (1998) compared two models of the TCI: a four-factor correlated model comprising the original four factors, as stated above; and a five-factor correlated model in which participation was replaced with two factors - participative safety, and interaction frequency.

Participative safety implies an inclusive and interpersonally safe workgroup environment, while interaction frequency is self-explanatory. Anderson and West (1998) found that both the four- and five-factor TCI models fit the data well, with negligible differences in fit between them. Anderson and West (1998) finally settled for the five-factor TCI model to maximize predictive utility, and called for future research to confirm the dimensionality of the TCI. Further, they noted that (West and Anderson, 1996; Anderson and West, 1998): a single factor may underlie the TCI factors, but argued they are best conceptualized as a correlated set; and that the TCI factors are likely to be useful in predicting other facet-specific workgroup climates. A recent systematic review and critique of the 
organizational climate literature by Kuenzi and Schminke (2009) showed that facet-specific work

157 climates can - and do - have effects beyond their immediate facet-specific outcomes. Studies

158 examining the dimensionality of the TCI have found support for both four- and five-factor TCI

159 models, and at both individual and workgroup levels of analysis (e.g. Mathisen et al., 2004; Mathisen

160 et al., 2006). Mathisen et al. (2006: 32) also found that a second-order one-factor TCI model "showed

161 almost comparable fit at both individual and team levels to the first-order four-factor model".

162 Therefore, they concluded that a multidimensional latent variable approach to work climate might

163 hold much promise. However, it is argued that interaction frequency per se, as a separate climate

164 dimension, is conceptually redundant since frequent interaction is an inherent characteristic of the

165 proximal workgroup in joint-production contexts (cf. Anderson and West, 1998: 236; Lindenberg and

166 Foss, 2011).

Carson et al. (2007) studied the effects of the 'internal team environment' and 'external

coaching' on shared leadership and team performance. They conceptualized 'internal team

environment' as a superordinate multidimensional construct with 'shared purpose', 'social support', and 'voice' as its first-order reflective dimensions. Carson et al.'s (2007: 1222) shared purpose, defined as similar understandings of and focus on collective goals, is conceptually equivalent to common goals in the present study. Carson et al. (2007: 1222) defined social support as 'team members' efforts to provide emotional and psychological strength to one another" and voice, as "the degree to which a team's members have an input into how the team carries out its purpose". Thus, social support and voice are subsumed under the integrative interactions dimension in the present study. Carson et al.'s (2007) conceptualization of internal team environment does not, therefore, include equal status and 
teamwork climate construct, with global individual- and group-level outcomes (see Fig. 1). As the review by Anvuur and Kumaraswamy (2007) shows, the teamwork climate dimensions are also germane to the joint-production context of construction TMO workgroups, and have each been common goals, equal status, integrative interactions, and authority support in multidimensional construct designs, and with individuals' cooperation as an outcome. Within the CMR literature, there is, to the best of the authors' knowledge, no multidimensional study of the teamwork climate factors. multidimensional teamwork climate construct to individuals' cooperation with their TMO workgroups. The present study also constitutes useful validation of the conceptual framework in Fig. confidence in its substantive utility and deployment. The individual level of analysis is adopted in this paper. Cooperation is conceptualized as individuals' performance behaviors that advance the goals of their proximal workgroups, and has four dimensions in terms of whether and to what extent roleincumbents (Tyler and Blader, 2001): creditably perform their work roles (in-role behavior); go the extra mile and undertake extra task activities or help colleagues with their work-related problems (extra-role behavior), adhere comprehensively to work-related rules and procedures (compliance behavior), and defer to relevant authorities or 'best practice' standards of appropriate conduct where rules or norms are non-existent or vague (deference behavior). The four performance behaviors are context-specific and constitute distinct, yet interrelated manifestations of the cooperation of individuals' with their workgroups. The construct validity and substantive utility of this four-dimensional conceptualization 
of cooperation in construction has been established in previous studies (e.g. Anvuur and

202 Kumaraswamy, 2012; Anvuur et al., 2012).

203

Fig. 1 about here

205

206

\section{Hypotheses}

Hypotheses connecting climates to individuals' cooperation were already tenable in the extant

literature before the present study. For example, within the extant literature, justice climate (e.g.

Naumann and Bennett, 2000; Liao and Rupp, 2005; Walumbwa et al., 2008) and involvement climate

(e.g. Richardson and Vandenberg, 2005) have been shown to predict individuals' extra-role behaviors.

Within project contexts, Thamhain (2004) found that the project team environment positively

influenced team performance in the 76 technology-based project teams he studied. Thamhain (2004)

operationalized project team environment as including factors such as professional recognition,

respect and senior management support; these factors are reflected in the equal status and authority

support dimensions of the teamwork climate construct in the present study. In their study of the social

network basis of knowledge management in project contexts, Brookes et al. (2006) found that

professional respect was significantly correlated with the effective sharing of information and

knowledge among workgroup members, what they termed relationship "conductivity". Using a

survey sample of 380 built environment managers nested in 115 construction teams, Tuuli and

Rowlinson (2009) examined the multi-level effects of empowerment climate on individuals' in-role 
and an opportunity to thrive. Their conceptualization of empowerment climate is, thus, consistent with the conceptualization of authority support in the present study. Tuuli and Rowlinson (2009) found that empowerment climate significantly and positively influenced individuals' in-role and extra-role behaviors, both directly and indirectly (through psychological empowerment). Thus, on the basis of previous research, and consistent our conceptual model, teamwork climate is expected to influence all four dimensions of an individual's cooperation with the workgroup; more formerly, we hypothesize thus:

Teamwork climate will significantly and positively influence TMO workgroup members' in-role $\left(H_{1}\right)$, extra-role $\left(H_{2}\right)$, compliance $\left(H_{3}\right)$, and deference behaviour $\left(H_{4}\right)$.

Further, this research seeks to inform this debate in the extant literature about whether the teamwork climate construct is best represented by its dimensions as a set or as a multidimensional construct. As noted earlier, Pettigrew and Tropp's (2006) meta-analytic study concluded that the four teamwork climate dimensions - common goals, equal status, integrative interactions, and authority support-are best conceptualized as an "interrelated bundle", with authority support being "may be an especially important for facilitating positive contact effects" (p.766). West $(1996 ; 1998)$ concluded that the four factors are best conceptualized as a correlated set, and also suggested a primary role for authority support. In contrast, Carson et al. (2007; also see Daspit et al., 2013) modeled, and found support for 'internal team environment' as a superordinate construct, although that construct tapped only two dimensions of climate: common goals (i.e. 'shared purpose') and integrative interactions (i.e. 'social support' and 'voice'). This stalemate about how to model the teamwork climate construct reflects a rift between maximizing predictive utility (i.e. using a multivariate structural model), and 
245 providing theoretical parsimony and bandwidth (i.e. using a superordinate or aggregate model) (Law

246 et al., 1998; Edwards, 2001). The lack of consensus on the conceptualization of the teamwork climate

247 dimension also reflects a broader debate in the literature about the utility of multidimensional

248 constructs relative to their dimensions. Edwards (2001) concluded that, although the available

249 evidence to date is stacked against their use, questions about the substantive utility of

250 multidimensional constructs in organizational behavior research can - and should - be examined

251 empirically; we do so in this study for the teamwork climate construct, using the integrative analytical

252 framework proposed by Edwards (2001) and two cross-cultural samples, one from the UK $(N=381$;

253 hereafter Study 1) and the other from Hong Kong ( $N=140$; hereafter, Study 2$)$. The methods of

254 research used in Studies 1 and 2 are discussed in the following section.

255

256

Fig. 2 about here

257

258 Method

259

Sample and procedure

260

Study 1

261

The questionnaire responses analyzed in Study 1 were from 381 chartered built environment

262 professional managers in the UK. Average age of the participants was 50 years. Average total

263 experience of the participants in construction was 30 years and average experience in current position was 11 years. All participants held managerial positions in the projects on which they reported, and all but 55 of them had at least a bachelor's degree. The sample consisted of 362 Caucasians, 8 Asians, 8 Africans and 3 participants of other ethnicities. This sample included 366 men and 15 women. The 
proportion of women managers in the sample (about $4 \%$ ) compares reasonable well with the total proportion of women employed in the UK construction sector (about 10\%, see Worrall et al., 2010).

Items for this Study 1 were merged into a larger questionnaire instrument that was itself a conceptual replication of an earlier Hong Kong based study (see Anvuur, 2008). A focus group discussion involving senior academic colleagues was used to make further refinements to the broader questionnaire instrument to make it more appropriate to the UK context. The final questionnaire instrument was entitled "Research Study into Impact of Professional Relations on Performance in Projects" to reflect the broader aims of the study. Data collection for study 1 was undertaken between July and September 2010.

The aim was to survey built environment professional managers in the UK who have recent project experience. As the theoretical population was unknown, a study population was defined using the following sampling procedure: First, the accessible population was defined as UK-based chartered (i.e. with 'Member' or 'Fellow' designation) built environment professional managers with project management expertise. Second, we searched the accessible professional membership directories such as the Chartered Institute of Building, and the Royal Institution of Chartered Surveyors, for chartered professionals with project management as a specialism, and who also have full postal or email addresses. This resulted in a sampling frame of 4290 professionals. We randomly selected 2000 professionals and invited them to participate in the study. Third, in order to identify and include only those with recent project experience, we asked respondents to indicate if they were directly involved in a construction project that was completed between 2005 and 2010 or currently ongoing but relatively advanced (yes/no). Respondents who answered 'yes' to the screening question (hereafter the 'eligibles') were asked to respond to the whole questionnaire. Those who answered 'no' (hereafter 
preference questions. The questionnaire items (save socio-demographic items) were tailored to a project context by expressly asking respondents to focus on their proximal TMO workgroup within one and the same specific project.

The postal questionnaire was printed as an A5 booklet and mailed to potential respondents

together with an enclosed business-reply envelope and a cover letter that detailed the particulars of the research study (i.e., researchers involved; purpose of study; nature of and how to the answer questions; importance and voluntary nature of participation; need for accuracy and assurances of confidentiality; data protection notice; approximate time to complete the survey; the aggregate nature of the ensuing data analyses and reporting; and when and how to return the completed questionnaire booklet). Some four hundred and forty-one (441) of those invited to participate in the study had email addresses, and were sent a link to a web version of the questionnaire developed in Opinio software; this granted customized content and anonymity to respondents. After two mailings (for the postal questionnaire) and two email reminders (for the web version), the following results were received: 405 'eligible' responses; 49 'non-eligible' responses; and 97 returned questionnaires. This represents a response rate of $21 \%$, or the higher rate of $23 \%$ when 'non-eligibles' in the sampling frame are adjusted for. As not all undelivered postal mails are returned, this response rate is a conservative estimate, and compares reasonably well with those reported for similar UK studies. For example, Ankrah et al. (2009) received a response rate of 15\% to their questionnaire survey; Bryde (2008) received a response rate of $12 \%$; and $\mathrm{Li}$ et al. (2005) received a response rate of $12 \%$ to their questionnaire study. appropriate remedies (Hair et al., 2010). This resulted in 21 cases being discarded for missing for more 
313 than $5 \%$ data. No noticeable missing data pattern was observed for the remaining 384 cases. Little's test of data missing completely at random (MCAR) was nonsignificant [ $\chi^{2} d f=14126=14364.25, p=.079$ ], indicating that there is no significant difference between the observed missing data pattern in the sample and a random pattern. At this stage, a further three cases were discarded for missing data on the non-metric control variables (i.e. gender, age, grade, nationality, ethnicity) in our study; two were missing data on all five control variables and the third, on nationality and ethnicity. The expectationmaximization data imputation method (cf. Hair et al., 2010) was used to impute replacement values for missing metric data. The binary logistic regression procedure in SPSS was used to statistically test the odds that six demographic variables and three project characteristics were related to high-effort ( $n$ $=123$ ) rather than low-effort (reference category; $n=258$ ) respondents. The results showed that no systematic differences existed between low-effort and high-effort respondents: nonsignificant ratio test $\left[\chi^{2}(d f=10)=8.301, p=.599\right] ;$ nonsignificant score test $\left[\chi^{2}(d f=10)=7.873, p=.641\right]$; nonsignificant associations between individual predictors and high-effort respondents ( $p>.05)$; nonsignificant Hosmer and Lemeshow (H-L) goodness-of-fit test $\left[\chi^{2}(d f=8)=3.105, p=.928\right]$. The presence of social desirability bias in the data was tested using Strahan and Gerbasi's (1972) 10-item short version of the 33-item Marlowe-Crowne Social Desirability scale (Crowne and Marlowe, 1960). Social desirability bias is bias that is associated with self-reported survey data, and exists because of a general human tendency to obey demand characteristics ('fake good') when self-reporting attitudes and behaviors (Mitchell and Jolley, 2001). All the Pearson's correlations $(N=381)$ were near zero (i.e., $r<|0.20|)$ and statistically nonsignificant $(p>.05)$, suggesting that the study constructs are not significantly tainted with social desirability bias (Mitchell and Jolley, 2001). The results of the data examination provide methodological and empirical reasons to believe that the analysis sample of 381 cases was not biased and is suitable for the subsequent analyses. 
The questionnaire responses analyzed in Study 2 were from 140 chartered built environment

professional managers in Hong Kong. The average age of the participants was 44 years. The average

total experience of the participants in construction was 20 years and average experience in current

position was seven years. All participants held managerial positions in the projects on which they

reported, and all but three of them had at least a bachelor's degree. The sample comprised 101

342

Chinese, 37 Caucasians and two participants of other ethnicities. The gender composition of the sample was 135 male and 5 female participants.

The survey instrument design, data collection and examination procedures were similar to

those in Study 1, and have been described in detail elsewhere (Anvuur and Kumaraswamy, 2012;

Anvuur et al., 2012). Items were drawn from a larger Hong Kong questionnaire survey, data collection

for which commenced in November 2006 and ended in March 2007. The questionnaire was sent out to

1100 potential respondents randomly drawn from a sampling frame for a study population defined

using a purposive sampling procedure, as described earlier for Study 1 . Out of this number 153 valid

responses were received, representing a response rate of $18 \%$ or the higher rate of $20 \%$ when adjusted

for the 'non-eligibles' in the sampling frame. This response rate compares reasonably well with those

\section{Measures}

Items measuring the four dimensions of individuals' cooperation with their workgroups (in-

role, extra-role, compliance, and deference) were based on Anvuur and Kumaraswamy (2012) and were scored on a 5-point response format $(1=$ never to $5=$ very often $)$. In-role behaviour was measured 
Extra-role behaviour was assessed with four items, for example, 'I volunteer to do things that are not

359

360

361

362

363

364

365

366

367

368

369

370

371

372

373

374

375

376

377

378

379

380 required in order to help my workgroup'. Compliance behaviour was measured with three items. A

sample item reads 'I comply with work related rules and regulations'). Deference behaviour was

assessed with three items, for example, 'I willingly follow my project organization's policies'. See

Appendix (items 1-14) for scale items for the cooperation dimensions.

The teamwork climate dimensions (integrative interactions, authority support, common goals, and equal status) were measured with 19 items (items 15-33, Appendix) each scored on a 5-point response format $(1=$ strongly disagree to $5=$ strongly agree $)$. Integrative interactions implies frequent interactions among workgroup members in joint decision-making and problem-solving, and was measured using four items (items 15-18, Appendix) adapted from the 'interaction frequency' subscale $(\alpha=0.84)$ of Anderson and West's (1998) Team Climate Inventory (TCI). A sample item reads 'We meet frequently to talk both formally and informally'. Common goals was measured with six items (items 25-30, Appendix) adapted from the 11-item 'vision' subscale $(\alpha=0.94)$ of Anderson and West's (1998) TCI. The TCI vision subscale reflects the extent of clarity, sharedness, attainability and importance of workgroup objectives, and is consistent with the conceptualization of common goals in the present study (e.g. 'I very much agree with my workgroup's objectives'). Authority support reflects the extent of support of the authorities, procedures and norms for joint decision-making and problem solving in the workgroup. This was measured with six items (items 19-24, Appendix) adapted from Siegel and Kaemmerer's (1978) 'support for creativity' scale (split-half reliability =0.94). A sample item reads 'Our ability to function cooperatively is respected by the leadership'. Equal status in a workgroup context implies mutual recognition, appreciation of and opportunities for individuals' contributions to the workgroup effort. Equal status in a workgroup context implies mutual recognition, appreciation of and opportunities for input. This facet was measured in Study 1 with 
'participative safety' subscale and in Study 2, with four items that assessed equal status (items 31-34,

383 Appendix: Study 2) adapted from Tyler and Blader's (2001) 8-item 'respect for work' scale (e.g.

'Colleagues in my proximal workgroup value what I contribute at work').

attainment in order to account for these possible alternative explanations for the cooperation of individuals with the TMO project workgroups. In both Studies 1 and 2, gender and education were dummy-coded to test the effects of being female (i.e. male $=0$ ) and holding a postgraduate qualification (i.e. bachelor's and below $=0$ ), respectively, on in-role, extra-role, compliance, and deference behavior. Ethnicity was dummy-coded to test the effects of being Caucasian (i.e. non-

Caucasian $=0$ ) in Study 1 and Chinese (i.e. non-Chinese $=0$ ), while age was dummy-coded to test the effects of being older than 50 years (i.e. $\leq 50$ years $=0$ ) in Study 1 , and older than 40 years (i.e. $\leq 40$ years $=0)$ in Study 2 .

Instructions preceding the questionnaire items in both Studies 1 and 2 (save the demographic and social preference items) oriented respondents to focus on their role and proximal cross-functional workgroup within one and the same construction project that they were recently involved in within 5 years of survey date. This is in keeping with the conceptualizations of the teamwork climate and cooperation constructs, and also increases the accuracy of the measures by ensuring that they are specific to a TMO workgroup and by minimizing the potential impact of recall bias.

\section{Analysis procedure}

The statistical procedure used was structural equation modeling (SEM), using AMOS software (Arbuckle, 2011). The two-step approach to SEM (Anderson and Gerbing, 1992) was adopted. First, 
404 CFA model with the first-order latent constructs integrative interactions, authority support, common goals, and equal status loaded onto a superordinate latent construct (four-factor superordinate model). The fit to the data of our hypothesized four-factor superordinate model was compared with the fit to the data of competing and alternative models of teamwork climate: (1) a three-factor multidimensional model with the first-order latent constructs supported integrative interactions (combining the integrative interactions and authority support items), common goals, and equal status loaded on to a superordinate latent construct (three-factor superordinate model); (2) and a model with all the teamwork climate items loaded on to a single latent construct (one-factor model). All the models above also included the four dummy-coded control variables (ethnicity, age, gender, and education) and the four cooperation dimensions (in-role, extra-role, compliance, and deference). A scale was set for each first-order latent construct by fixing a path leading from the construct to unity and for each superordinate construct, by fixing its variance to unity, thereby standardizing it. The error variances for the dummy-coded variables were fixed to zero. Secondly, once a good-fitting CFA model was obtained, we proceeded to specify and test a structural model containing the hypothesized relations between the four-factor superordinate teamwork climate construct and each cooperation dimension.

As absolute values of univariate skewness and kurtosis for scale items were all below 2 and 7 respectively and the four dummy-coded control variables were fixed, maximum likelihood estimation was used (cf. Curran et al., 1996). When assessing absolute model fit, evidence of satisfactory fit for a CFA model of this complexity would include a significant $\chi^{2}$ value, a normed $\chi^{2}$ (i.e. $\chi^{2} / d f$ ) value below square error of approximation (RMSEA) value below 0.08 (cf. Hair et al., 2010). The measurement models described above are all nested and, therefore, were compared with one another using Chi- 
427

428

429

430

431

432

433

434

435

436

437

438

439

440

441

442

443

444

445

446

447

448

square difference tests. Good convergent validity is generally indicated by (Hair et al., 2010):

statistically significant factor loadings of 0.50 or higher; average variance extracted (AVE) estimates of 0.50 or higher; and construct reliability ( $\mathrm{CR}$; the conceptual equivalent to Cronbach's alpha) estimates of 0.70 or higher. Discriminant validity is demonstrated if the AVE estimate for each construct is greater than the squared interconstruct correlations associated with that construct (Hair et al., 2010).

\section{Results}

\section{Study 1}

CFA

The analysis confirmed a good overall fit of the four-factor teamwork climate CFA model to the data: $\chi^{2}(d f=593)=1132.83, p=.000 ; \chi^{2} / d f=1.91 ;$ RMSEA $=0.049 ;$ IFI $=0.93 ;$ CFI $=0.93$. This model was better fitting than a three-factor model with items measuring integrative interactions and authority support loaded onto a common factor $\left(\Delta \chi^{2}(1)=546.304, p=.000\right)$ and a one-factor model with all the teamwork climate items loaded onto a single factor $\left(\Delta \chi^{2}(4)=1359.9, p=.000\right)$. Both the one-factor and three-factor models did not fit the data well. (We also performed a Bollen-Stine bootstrap procedure with 5000 resamples to assess the overall CFA model fit to the data and obtained the same results as reported above for the normal theory test.) All standardized factor loadings ranged from 0.62 to 0.93 , and all freely estimated loadings were statistically significant at $p=.000$. The factor loadings of the teamwork climate indicators were substantially high (integrative interactions, $\lambda=0.80$; authority support, $\lambda=0.72$; common goals, $\lambda=0.69$; equal status, $\lambda=0.81$ ). The CR estimates for all latent constructs, presented in Table 1 , substantially exceeded the cut-off value of 0.70 , suggesting adequate reliability. All AVE estimates in Table 1 (diagonal entries) exceeded the 0.50 threshold value. Thus, overall, the evidence supports the convergent validity of the CFA model. In Table 1 it is clear to 
449

450

451

452

453

454

455

456

457

458

459

460

461

462

463

464

465

466

467

468

469

470

see that each AVE estimate is greater than the squared interconstruct correlations in the row or column in which it is found. Therefore, the discriminant validity of the CFA model is confirmed.

The pattern of statistically significant, positive correlations among the latent constructs in

Table $1(r \geq 0.24, p<.001)$, consistent with theoretical expectations, provides evidence of nomological validity on a zero-order basis. Of the four control variables, ethnicity was significantly associated with extra-role behavior $(r=0.26, p<.001)$ and age $(r=0.18, p<.001)$, age was also significantly related to teamwork climate $(r=0.20, p<.001)$, while education was significantly associated with compliance $(r=$ $0.11, p<.001)$ and gender $(r=0.11, p<.001)$.

Table 1 about here

\section{SEM}

Having established that the CFA model has a good fit to the data, we proceeded to test the structural model for corroboration (or otherwise) of hypotheses $H_{1}$ through to $H_{4}$. We also included paths from each of the four control variables (ethnicity, age, gender, and education) to in-role, extrarole, compliance, and deference behavior. The bias-corrected and accelerated bootstrap $\left(\mathrm{BC}_{a}\right)$ procedure with 5,000 resamples was used to generate the $95 \%$ confidence intervals and associated standard errors of parameter estimates. A parameter estimate is significant if its $95 \%$ bootstrap confidence interval does not include zero (Cheung and Lau, 2008). The results showed convergence between the normal theory sample estimates and the bootstrap estimates. The results also suggested a good fit of the structural model to the data: $\chi^{2}(d f=599)=1286.05, p=.000 ; \chi^{2} / d f=2.147 ; \mathrm{IFI}=0.91 ; \mathrm{CFI}=$ 0.91; RMSEA $=0.055$. The structural model is shown in Fig. 2 . To avoid visual clutter, the error terms 
471

472

473

474

475

476

477

478

479

480

481

482

483

484

485

486

487

488

489

490

491

492 for factor loadings and disturbance terms for latent constructs, as well as all the objects, names and parameters associated with the four control variables (ethnicity, age, gender and education) are not displayed in Fig. 2. However, an error or disturbance term is easily computed as 1 minus the squared multiple correlation. For example, the error term for indicator number $1, e_{1}=1-0.70=0.30$; and the disturbance term for the integrative interactions construct, $d_{1}=1-0.57=0.43$. All coefficients in Fig. 2 , including path coefficients and freely estimated factor loadings are statistically significant at $p<.001$.

The stability of parameter estimates between the CFA and SEM models (allowing for the expected insignificant factor loading fluctuations of $\leq|0.05|$ ) provides further evidence of discriminant validity. The structural path from ethnicity to extra-role behavior (not shown in Fig. 2) was statistically significant and positive $(\beta=0.23 ; 95 \% \mathrm{CI}=0.11,0.36 ; p=.000)$, suggesting that the Caucasian respondents in the sample engaged in more extra-role behavior than the non-Caucasians. No significant effects were found for the other control variables. Hypothesis $H_{1}$ predicted that teamwork climate would significantly and positively influence in-role behavior. The hypothesis was supported, as the structural path from teamwork climate to in-role behavior (see Fig. 2) was statistically significant and positive $\left(\beta=0.47 ; 95 \% \mathrm{CI}=0.34,0.60 ; p=.000 ; R^{2}=0.23\right)$. The results in Fig. 2 also show that: teamwork climate is significantly and positively related to extra-role $(\beta=0.49 ; 95 \% \mathrm{CI}=0.35,0.61$; $\left.p=.000 ; R^{2}=0.31\right)$, compliance $\left(\beta=0.57 ; 95 \% \mathrm{CI}=0.43,0.70 ; p=.000 ; R^{2}=0.33\right)$, and deference behavior $\left(\beta=0.52 ; 95 \% \mathrm{CI}=0.36,0.66 ; p=.000 ; R^{2}=0.27\right)$. Therefore, hypotheses $H_{2}, H_{3}$ and $H_{4}$ were also supported.

Fig. 2 about here 
conceptualization of teamwork climate. The relationships between dimension specificities and the

effects of the superordinate teamwork climate construct were assessed as the incremental variances

explained by integrative interactions, authority support, common goals, and equal status after

controlling for the superordinate teamwork climate construct (cf. Edwards, 2001). These were tested

using modification indices (MIs) for parameters directly linking integrative interactions, authority

support, common goals, and equal status to each cooperation dimension; these MIs are each chi-

square distributed with $d f=1$, and indicate the expected improvement in model fit if a constrained

(2001) to divide the nominal $p$-value of .05 by the number of MIs examined (i.e. $4 \times 4=16$ in the

present study) was followed, and this produced a critical $p$-value of .003125 and corresponding chisquare of 8.733 , for $d f=1$. The largest MI for all parameters directly linking integrative interactions, authority support, common goals, and equal status to each cooperation dimension was 4.692; that is,

all MIs were below the critical chi-square value of 8.733 . Therefore, the results show that after

controlling for the effect of the superordinate teamwork climate construct, there is no significant direct

\section{Discussion}



and, more generally, support the application of the conceptual framework developed by Anvuur and

517 Kumaraswamy (2007) to the problem of cooperation in construction projects. First, the results provide support for the construct validity of our superordinate multidimensional conceptualization of teamwork climate. Second, the results show that teamwork climate influences all four dimensions of an individual's cooperation with the workgroup. Third, the results of the additional analyses undertaken provide support for the substantive utility of the superordinate multidimensional teamwork climate construct in this study; they show that it is the shared variance in the teamwork climate dimensions, rather than their unique variances, that is instrumental in tapping into all facets of an individual's cooperative behavior. These findings are also very significant practically, in so far as they inform the ongoing debate about how best to improve the level of cooperation in and performance of projects the world over. the results of Study 1 are biased by the sample or its UK context, although we included statistical controls for the effects of ethnicity, age, gender and highest educational attainment. It was therefore important to test the hypotheses for corroboration in a different sample and context to that in Study 1. predominantly Chinese sample $(N=140)$ drawn from built environment professional managers in Hong Kong; given the smaller sample size, hence statistical power, Study 2 provides an even stricter test of the hypotheses in this research.

\section{Study 2}

\section{CFA}


$=629)=928.27, p=.000 ; \chi^{2} / d f=1.48 ; \mathrm{RMSEA}=0.059 ; \mathrm{IFI}=0.91 ; \mathrm{CFI}=0.91$. All standardized factor

loadings ranged from 0.61 to 0.97 , and all freely estimated loadings were statistically significant, $p=$

.000. This model fit the data better than a three-factor model in which the items measuring integrative

interactions and authority support were merged and loaded onto a common factor $\left(\Delta \chi^{2}(1)=175.00, p=\right.$

$.000)$ and a one-factor model with all the teamwork climate items loaded onto a single factor $\left(\Delta \chi^{2}(4)=\right.$

$552.63, p=.000)$. Neither the three-factor model nor the one-factor model fit the data well. The

standardized loadings ranged from 0.61 to 0.97 . The factor loadings for the superordinate teamwork

climate construct were substantially high (integrative interactions, $\lambda=0.76$; authority support, $\lambda=0.88$;

common goals, $\lambda=0.75$; equal status, $\lambda=0.75$ ). Table 2 shows the $C R s$, interconstruct correlations and

AVE estimates for the variables in the CFA model. The CR estimates for all latent constructs were substantially higher than the threshold value of 0.70 , thus suggesting adequate reliability. Except for extra-role, with an AVE estimate of 0.47, all AVE estimates in Table 2 exceeded the threshold value of

0.50. The below-threshold AVE estimate for extra-role is despite its substantially high CR estimate of

0.86. However, it is not uncommon for acceptably reliable latent constructs to have below-threshold AVE estimates (Hair et al., 2010). Overall, however, the evidence supports the convergent validity of the CFA model. that each AVE estimate is greater than the squared interconstruct correlations in the row and column in which it is found. The pattern of statistically significant, positive correlations among latent constructs in Table $2(r \geq 0.22, p<.05)$, consistent with theoretical expectations, provides evidence of nomological validity on a zero-order basis. Of the four control variables, ethnicity was significantly associated with extra-role behaviour $(r=0.19, p<.05)$ and compliance $(r=0.20, p<.05)$, age was 
561 significantly related to gender $(r=-0.19, p<.05)$, and education was significantly associated with 562 compliance $(r=0.19, p<.05)$.

563

564

Table 2 about here

565

566

SEM

567

Having established satisfactory fit of the CFA model to the data, we proceeded to test the

structural model for corroboration (or otherwise) of hypotheses $H_{1}$ through to $H_{4}$. The SEM model also

569

included paths from each of the four control variables (ethnicity, age, gender, and education) to in-

role, extra-role, compliance, and deference behavior. The results suggested a good fit of the SEM

571

model to the data: $\chi^{2}(d f=634)=970.42, p=.000 ; \chi^{2} / d f=1.53 ; \mathrm{IFI}=0.90 ; \mathrm{CFI}=0.90 ; \mathrm{RMSEA}=0.06$. The

572

structural model is shown in Fig. 3. Numbers (1-34) are used to represent scale items for first-order

573

constructs in Fig. 3. All coefficients for the variables of interest in Fig. 3, including path coefficients

574

and freely estimated factor loadings were statistically significant at $p<.05$. The stability of parameter

575

estimates between the CFA and SEM models (allowing for the expected insignificant factor loading

576

fluctuations of $\leq|0.05|$ ) provides further evidence of discriminant validity.

577

Except the statistically significant and positive effect of education on compliance behavior $(\beta=$

578

$0.17, p=.037$ ) (not shown in Fig. 3), no significant effect was found for the other control variables. We

579

found support for our substantive hypotheses. Hypothesis $H_{1}$ predicted that teamwork climate would

580

significantly and positively influence in-role behavior. This was supported, as the structural path from

581

teamwork climate to in-role behavior (see Fig. 3) was statistically significant and positive $(\beta=0.45, p=$

582

$\left..000 ; R^{2}=0.19\right)$. The results in Fig. 3 also show that: teamwork climate is significantly and positively 
related to extra-role $\left(\beta=0.62, p=.000 ; R^{2}=0.37\right)$, compliance $\left(\beta=0.23, p=.015 ; R^{2}=0.13\right)$, and deference

584 behavior $\left(\beta=0.24, p=.019 ; R^{2}=0.11\right)$. Therefore, hypotheses $H_{2}, H_{3}$ and $H_{4}$ were also supported.

585

586

587

588

589

590

591

592

593

594

595

596

597

598

599

600

601

602

603

604
Fig. 3 about here

We again performed supplemental analyses to test the substantive utility of our superordinate multidimensional conceptualization of teamwork climate, using the same procedure as described early for Study 1. We compared the largest MI for all parameters directly linking integrative interactions, authority support, common goals, and equal status to each cooperation dimension the critical $p$-value of .003125 and corresponding chi-square of $8.733, d f=1$ (cf. Edwards, 2001). The largest MI observed was 1.770, which below the critical chi-square value of 8.733 ; thus suggesting that, there is no unique effect of integrative interactions, authority support, common goals, or equal status on any dimension of individuals' cooperation. Also, the results show that the criterion-related validity of the teamwork construct is not significantly different from that of its dimensions as a set. Again, these results provide further support for our superordinate multidimensional conceptualization of teamwork climate.

\section{Discussion}

The results of Study 2 corroborate those of Study 1, and support the four hypotheses examined in this research. The results also provide support for the superordinate multidimensional conceptualization of teamwork climate in this research. The results of Study 2, like those for Study 1, show that teamwork climate influences all four types of cooperative: in-role, extra-role, compliance, and deference behaviour. There is a marked difference, however, in the amount of unique variance in 
605

606

607

608

609

610

611

612

613

614

615

616 compliance and deference explained by teamwork climate between Study 1 and Study 2: for compliance, $32 \%\left(=.57^{2} \times 100\right)$ in Study 1 against $5 \%\left(=.23^{2} \times 100\right)$ in Study 2 ; and for deference, $27 \%$ $\left(=.52^{2} \times 100\right)$ in Study 1 against $6 \%\left(=.24^{2} \times 100\right)$ in Study 2 . This may be because the superordinate multidimensional teamwork climate construct has a smaller proportion of relevant variance shared with the control variables in Study 1 than in Study 2.

The results of Study 2, like those of Study 1, demonstrate the convergent, discriminant, and nomological validities of the superordinate multidimensional teamwork climate construct. Beyond just demonstrating its construct validity, Study 2 indicates the substantive utility of the superordinate multidimensional conceptualization of teamwork climate. The results of the supplemental analyses in Study 2, like those of Study 1, show that after accounting for the effects of the superordinate multidimensional teamwork climate construct, there is no unique, significant effect of any of its dimensions on cooperative behavior. Thus, the results of Study 1 and Study 2, undertaken in different contexts and with different sample sizes, are reinforcing in their support for the four hypotheses examined in this research, and the construct validity and theoretical parsimony of the superordinate multidimensional conceptualization of teamwork climate.

\section{General Discussion}

The two studies reported in this paper make an important contribution to research on how to foster engagement in workgroups, and our collective understanding of the behavioral implications of a teamwork climate in project contexts. They do so by showing that teamwork climate significantly and positively influences all four dimensions of a role-incumbent's cooperation with the TMO workgroup. These findings are consistent with the emphasis in Anvuur and Kumaraswamy's (2007) conceptual model (see Fig. 1) on the formative role of a salient teamwork climate in TMO workgroup 
contexts; the results provide sound empirical support for the model's proposition. The findings are also consistent with those of previous research on the behavioral implications of work climates in general (Richardson and Vandenberg, 2005; e.g. Walumbwa et al., 2008; cf. Kuenzi and Schminke, 2009) and specifically, they extend previous CMR studies (e.g. Brookes et al., 2006; cf. Anvuur and Kumaraswamy, 2007; Tuuli and Rowlinson, 2009) that have connected aspects of the TMO workgroup environment with members' cooperative behaviors.

The two studies reported in this paper further contribute to research on work climates by demonstrating the value of a superordinate multidimensional conceptualization of teamwork climate. They show that, after controlling for the superordinate multidimensional teamwork climate construct, none of its four dimensions explains any incremental variance in an individual's cooperative behavior. Thus, in contrast to the suggestion of previous research (e.g. West and Anderson, 1996; Anderson and West, 1998; Pettigrew and Tropp, 2006), the present research demonstrates that a superordinate multidimensional conceptualization of teamwork climate does not result in any loss of predictive utility; in other words, our superordinate multidimensional conceptualization of teamwork climate maximizes predictive utility, parsimony, and bandwidth (cf. Edwards, 2001). Also, these and other findings discussed earlier on the criterion validity of the teamwork climate construct challenge previous suggestions (see e.g. West and Anderson, 1996; Anderson and West, 1998; Pettigrew and Tropp, 2006) about the primacy of authority support over the other three dimensions of this superordinate multidimensional construct. Further, support for the superordinate multidimensional conceptualization of teamwork climate in this research responds to the call for multiclimate or hierarchical models of climate, as a response to the fragmentation in climate research caused by the proliferation of facet-specific climates (Kuenzi and Schminke, 2009). 
Kong) and different measures for equal status represents a constructive replication, and provides the strongest test of the hypotheses in this study (Lykken, 1968). That the findings from Studies 1 and 2 converge in providing full support for the multidimensional teamwork climate construct and its hypothesized effects also provides evidence of their generalizability. The results for the control variables (i.e. ethnicity, age, gender and education) in this research indicate significant effects only for ethnicity in Study 1 and education in Study 2. They show that Caucasian respondents in Study 1, compared to non-Caucasians, exhibited more extra-role behavior. Also, respondents with a post bachelor qualification in Study 2, compared to those without one, exhibited more compliance behavior. The results for the control variables may seem somewhat surprising. Indeed, on the basis of previous research, the findings of no effect for rule-following (i.e. compliance, deference behavior) for Chinese, when compared to non-Chinese respondents in the Study 2 sample (cf. Hofstede et al., 2010), and of a positive effect for extra-role for Caucasian, when compared non-Caucasian respondents in the Study 1 sample (e.g. Moorman and Blakely, 1995) were unexpected. A plausible explanation for the finding of no effect of being Chinese on rule-following behavior in Study 2 and for the significant reduction in variance for rule-following behavior explained by the multidimensional teamwork climate construct from Study 1 to Study 2 (i.e. average $\Delta R^{2}$ from $30 \%$ to $6 \%$ ) is that the multidimensional teamwork climate construct (and its dimensions) overlaps with the fundamental tenets of Chinese culture, such as collectivism and guanxi (e.g. Peng and Luo, 2000; cf. Hofstede et al., 2010; Anvuur et al., 2012). Future research may usefully verify the current findings for the control variables in this research; however, the control variables per se are not of interest in this research, although their inclusion allowed us to take account of these alternative explanations for respondents' cooperative behaviors. 
672

673

674

675

676

677

678

679

680

681

682

683

684

685

686

687

688

689

690

691

692

693

694

\section{Practical implications}

The findings of this research suggest that the presence and salience of a teamwork climate has the capacity to unlock the full spectrum of individuals' cooperative behaviors in TMO workgroup contexts. Thus, the findings have important practical implications for project managers trying to build and sustain high-performance project teams. First, project managers must be heedful of the development (or lack thereof) of common goals, equal status, integrative interactions, and authority support in their TMO workgroups. Second, while progress in the development of any one of these dimensions of climate may yield one or more of the associated positive outcomes (West and Anderson, 1996; Pettigrew and Tropp, 2006; for a review of evidence in CMR, cf. Anvuur and Kumaraswamy, 2007; e.g. Carson et al., 2007), our findings show that it is the combined and balanced pursuit of all four dimensions of climate, rather than one or another of them in isolation, that is key to unlocking the full gamut of an individual's cooperative behavior in project settings. These insights are critical, as they show that the development of a teamwork climate must be central to efforts to improve the level of cooperation in projects; efforts that embody the partnering ethos (Anvuur and Kumaraswamy, 2007).

Application of these insights, requires, consistent with the conceptual framework proposed by Anvuur and Kumaraswamy (2007, see Figure 1), the deployment of targeted strategies -including training, coaching and facilitation - for the development of the conditions and relevant cognitive cues for the perception of common goals, equal status, integrative interactions, and authority support (i.e. a teamwork climate). These insights and the conceptual model shown in Fig. 1, thus, provide a framework for understanding the concept of partnering and for sensegiving in its practice; sensegiving as used here refers to efforts to guide the "meaning construction of others toward a preferred redefinition of an organizational reality" (cf. Gioia and Chittipeddi, 1991:442). For a 
discussion on how the processes of enactment, sensegiving and sensemaking implicated in Fig. 1 can contribute to the much desired 'cultural transformation' of the construction sector as a whole, the reader is referred to Anvuur and Kumaraswamy (2007).

\section{Limitations and future research}

The usual limitations of any research of the kind reported in this paper apply; these limitations

derive, principally, from the self-report nature of the data, sample demographics and location

specificity of each study, and are best left to future research to address. However, the key concerns

posed by these limitations may (i.e. effect size inflation, generalizability of findings) were mitigated in

this study through the use of two cross-cultural samples, statistical controls, as well as the established

procedural remedies for dealing with them (see "Method" section). Also, while our findings are

consistent with our hypotheses, the extant literature and the causal directions depicted in our

conceptual model, they do not prove causality. Therefore, corroboration of our findings by future

research would be useful.

The focus in this research has been on psychological climate, that is, individuals' perceptions of their workgroup environment. While this has provided very useful insights, a useful extension to this research would be to test the same hypotheses at the workgroup level-that is, for collective perceptions of the work climate. Admittedly, surveying multiple respondents from different TMO workgroups will be very challenging but also might yield more insights beyond just corroborating the findings in the current research. Indeed, previous research has found different levels of the same outcomes for individual perceptions versus aggregated perceptions of climate phenomena (cf. Kuenzi and Schminke, 2009). Although our explanation above for the significant difference in variance for rule-following behavior explained by the teamwork climate construct between the predominantly 
718 plausible and founded in previous research, future research could usefully shed more light on the

719 precise role of culture in perceptions of teamwork climate. Nevertheless, the findings of the present

720 research provide important insights into how to foster the cooperation of individuals with their TMO

721 workgroups.

\section{Conclusion}

723

724

725

726

727

728

729

730

731

732

733

734

735

736

737

738

739

Anvuur and Kumaraswamy (2007) developed a conceptual model of partnering and alliancing that placed emphasis on common goals, equal status, integrative interactions, and authority support as being the optimal climate factors for effective teamwork in construction projects. Although the four climate factors are well established in parallel lines of extant literature, they have not previously been empirically tested simultaneously in the context of cross-functional TMO workgroups. Also, while there is agreement in the extant literature that the four climate factors are interrelated, there is as yet no consensus on precisely how they should be conceptualized: as distinct but related dimensions of a single theoretical concept (i.e. multidimensional construct); or as distinct but related concepts (i.e. multivariate set); this lack of consensus on the conceptualization of the teamwork climate factors is against the backdrop of a broader debate in the extant literature about the utility of multidimensional constructs relative to their dimensions.

In response, this research conceptualized the four climate factors as the dimensions of a superordinate multidimensional latent construct, teamwork climate, and empirically tested the effects of this multidimensional construct and its dimensions on individuals' cooperation with their TMO workgroups in two field studies of built environment professional managers in the UK and Hong Kong. The results of the two studies demonstrate the convergent, and discriminant validity of the multidimensional teamwork climate construct, and show that teamwork climate significantly and 
positively influences in-role, extra-role, compliance, and deference behaviour. Further, the results show that the common goals, equal status, integrative interactions, and authority support dimensions as a set neither explain any incremental variance in cooperative behavior nor possess any incremental criterion-related validity over and above the multidimensional teamwork work construct. These findings constitute significant contributions to knowledge in so far as they show that: (a) teamwork climate is a primary determinant of all dimensions of individuals' cooperative behavior in their TMO workgroups, hence provide strong support for the application in TMO settings of the conceptual model developed by Anvuur and Kumaraswamy (2007); (b) a superordinate multidimensional conceptualization of teamwork climate not only is viable, but also, at least in this research, maximizes predictive utility and provides theoretical parsimony and bandwidth; and (c) when considering managerial interventions to foster greater engagement in TMO workgroups, practicing project managers must focus attention on creating the generative project environments for the development, maintenance and perception of common goals, equal status, integrative interactions, and authority support.

\section{Acknowledgements}

Grant HKU7138/05E from the Hong Kong Research Grants Council supported data collection for Study 2. An earlier version of this paper, based on the Hong Kong sample only, was presented at the 19th CIB World Building Congress 2013 held in Brisbane, Australia.

\section{References}

Allport, G.W. (1954) The nature of prejudice. Cambridge, Mass: Addison-Wesley. 
Anderson, N.R. and West, M.A. (1998) Measuring climate for work group innovation: development

763

764

765

766

767

768

769

770

771

772

773

774

775

776

777

778

779

780

781

782

783

784 and validation of the team climate inventory. J. Organ. Behave., 19(3), 235-258.

Ankrah, N.A., Proverbs, D. and Debrah, Y. (2009) Factors influencing the culture of a construction project organisation: an empirical investigation. Eng. Const. Arch. Manage., 16(1), 26-47.

Anvuur, A.M. (2008) Cooperation in construction projects: concept, antecedents and strategies, Unpublished PhD thesis, Department of Civil Engineering, The University of Hong Kong.

Anvuur, A.M. and Kumaraswamy, M.M. (2007) Conceptual model of partnering and alliancing. J. Constr. Eng. Manage., 133(3), 225-234.

Anvuur, A.M. and Kumaraswamy, M.M. (2012) Measurement and antecedents of cooperation in construction. J. Constr. Eng. Manage., 138(7), 797-810.

Anvuur, A.M., Kumaraswamy, M.M. and Fellows, R. (2012) Perceptions of status and TMO workgroup cooperation: implications for project governance. Constr. Manage. Econ., 30(9), 719-737.

Arbuckle, J.L. (2011) Amos (Version 20). Chicago: IBM SPSS.

Brookes, N.J., Morton, S.C., Dainty, A.R.J. and Burns, N.D. (2006) Social processes, patterns and practices and project knowledge management: A theoretical framework and an empirical investigation. Int. J. Proj. Manage., 24(6), 474-482.

Bryde, D.J. (2008) Is construction different? A comparison of perceptions of project management performance and practices by business sector and project type. Constr. Manage. Econ., 26(3), 315 327.

Carson, J.B., Tesluk, P.E. and Marrone, J.A. (2007) Shared leadership in teams: an investigation of antecedent conditions and performance. Acad. Manage. J., 50(5), 1217-1234.

Cheung, G.W. and Lau, R.S. (2008) Testing mediation and suppression effects of latent variables: bootstrapping with structural equation models. Organ. Res. Methods, 11(2), 296-325. 
Crowne, D.P. and Marlowe, D. (1960) A new scale for social desirability independent of psychopathology. J. Consult. Psychol., 24, 349-354.

787

Curran, P.J., West, S.G. and Finch, J.F. (1996) The robustness of test statistics to nonnormality and specification error in confirmatory factor analysis. Psychol. methods, 1(1), 16-29.

Daspit, J., Tillman, C.J., Boyd, N.G. and McKee, V. (2013) Cross-functional team effectiveness: An examination of internal team environment, shared leadership, and cohesion influences. Team Perform. Manage., 19(1), 34-56.

792 a meta-analysis. J. Appl. Psychol., 95(1), 32-53.

Dulaimi, M.F. and Langford, D. (1999) Job behaviour of construction project managers: determinants and assessment. J. Constr. Eng. Manage., 125(4), 256-264.

Edwards, J.R. (2001) Multidimensional constructs in organisational behaviour research: an integrative 797 analytical framework. Organ. Res. Methods, 4(2), 144-192.

Fellows, R. and Liu, A.M.M. (2013) Use and misuse of the concept of culture. Constr. Manage. Econ., 31(5), 401-422.

800

Gaertner, S.L. and Dovidio, J.F. (2000) Reducing intergroup bias: the common ingroup identity model. Philadelphia, PA: Psychology Press.

802

803

Gioia, D.A. and Chittipeddi, K. (1991) Sensemaking and sensegiving in strategic change initiation. Strateg. Manage. J., 12(6), 433-448.

Hair, J.F., Black, W.C., Babin, B.J. and Anderson, R.E. (2010) Multivariate data analysis: a global 805 perspective. 7th ed. Upper Saddle River, NJ: Pearson/Prentice Hall. 689-710. 
Hofstede, G., Hofstede, G.J. and Minkov, M. (2010) Cultures and organizations: software of the mind. 3rd Edition ed. New York, NY: McGraw-Hill USA.

810 Kuenzi, M. and Schminke, M. (2009) Assembling fragments into a lens: a review, critique, and proposed research agenda for the organizational work climate literature. J. Manage., 35(3), 634-717.

Law, K.S., Wong, C.-S. and Mobley, W.H. (1998) Toward a taxonomy of multidimensional constructs. Acad. Manage. Rev., 23(4), 741-755.

Lawrence, P.R. and Lorsch, J.W. (1967) Organization and environment : managing differentiation and integration. Boston: Division of Research, Graduate School of Business Administration, Harvard University.

Li, B., Akintoye, A., Edwards, P.J. and Hardcastle, C. (2005) Critical success factors for PPP/PFI projects in the UK construction industry. Constr. Manage. Econ., 23(5), 459-471.

Liao, H. and Rupp, D.E. (2005) The impact of justice climate and justice orientation on work outcomes: a cross-level multifoci framework. J Appl Psychol, 90(2), 242-56.

Lindenberg, S. and Foss, N.J. (2011) Managing joint production motivation: The role of goal framing and governance mechanisms. Acad. Manage. Rev., 36(3), 500-525.

Lykken, D.T. (1968) Statistical significance in psychology research. Psychol. Bull., 70(3, Pt. 1), 151-159.

Mathisen, G.E., Torsheim, T. and Einarsen, S. (2006) The team-level model of climate for innovation: a two-level confirmatory factor analysis. J. Occup. Organ. Psych., 79(1), 23-35. 383-92. College Publishers. 
831

Mohammed, S., Ferzandi, L. and Hamilton, K. (2010) Metaphor no more: a 15-year review of the team mental model construct. J. Manage., 36(4), 876-910.

833

Moorman, R.H. and Blakely, G.L. (1995) Individualism-collectivism as an individual difference predictor of organizational citizenship behavior. J. Organiz. Behav., 16(2), 127-142.

Naumann, S.E. and Bennett, N. (2000) A case for procedural justice climate: development and test of a multilevel model. Acad. Manage. J., 43(5), 881-889.

Peng, M.W. and Luo, Y. (2000) Managerial ties and firm performance in a transition economy: the nature of a micro-macro link. Acad. Manage. J., 43(3), 486-501.

Pettigrew, T.F. (1998) Intergroup contact theory. Annu. Rev. Psychol., 49, 65-85.

Pettigrew, T.F. and Tropp, L.R. (2006) A meta-analytic test of intergroup contact theory. J. Pers. Soc. Psychol., 90(5), 751-783.

Phua, F.T.T. (2004) The antecedents of co-operative behaviour among project team members: an alternative perspective on an old issue. Constr. Manage. Econ., 22(10), 1033-1045.

Richardson, H.A. and Vandenberg, R.J. (2005) Integrating managerial perceptions and transformational leadership into a work-unit level model of employee involvement. J. Organiz. Behav., 26(5), 561-589.

Salas, E., Cooke, N.J. and Rosen, M.A. (2008) On teams, teamwork, and team performance: discoveries and developments. Hum. Factors, 50(3), 540-547.

Schneider, B. and Reichers, A.E. (1983) On the etiology of climates. Pers. Psychol., 36(1), 19-39.

Schneider, B., Ehrhart, M.G. and Macey, W.H. (2013) Organizational climate and culture. Annu. Rev. Psychol., 64(1), 361-388.

Siegel, S.M. and Kaemmerer, W.F. (1978) Measuring the perceived support for innovation in organizations. J. Appl. Psychol., 63(5), 553-562. 
854 Strahan, R. and Gerbasi, K.C. (1972) Short, homogeneous versions of the Marlowe-Crowne social

855 desirability scale J. Clin. Psychol., 28(2), 191-193.

856 Thamhain, H.J. (2004) Linkages of project environment to performance: lessons for team leadership.

857 Int. J. Proj. Manage., 22(7), 533-544.

858 Tjosvold, D., Wedley, W.C. and Field, R.H.G. (1986) Constructive controversy, the Vroom-Yetton

859 model, and managerial decision- making. J. Occup. Behav., 7(2), 125-138.

860 Tuuli, M.M. and Rowlinson, S. (2009) Empowerment in project teams: a multilevel examination of the 861 job performance implications. Constr. Manage. Econ., 27(5), 473 - 498.

862 Tyler, T.R. and Blader, S.L. (2001) Identity and cooperative behaviour in groups. Group Process Interg., $863 \quad 4(3), 207-226$.

864 Walumbwa, F.O., Wu, C. and Orwa, B. (2008) Contingent reward transactional leadership, work

865 attitudes, and organizational citizenship behavior: The role of procedural justice climate

866 perceptions and strength. Leadership Quart., 19(3), 251-265.

867 West, M.A. (1990) The social psychology of innovation in groups. In: West, M.A. and Farr, J.L. (Eds.),

868 Innovation and creativity at work : psychological and organizational strategies, pp. 4-36. Chichester,

869 England: Wiley.

870 West, M.A. and Anderson, N.R. (1996) Innovation in top management teams. J. Appl. Psychol., 81(6),

$871 \quad 680-693$

872 Worrall, L., Harris, K., Stewart, R., Thomas, A. and McDermott, P. (2010) Barriers to women in the UK 873 construction industry. Eng. Const. Arch. Manage., 17(3), 268-281.

874

875 Appendix: Construct measures 


\section{Dependent variables}

Note: Instructions preceding these measures guided respondents to answer the questions with regard to their proximal cross-functional workgroup in the referent project and their role within that workgroup. Items are numbers correspond with those in Figures 1 and 2.

In-role. How often have you ( $1=$ 'never' to $5=$ 'very often'): (1) fulfilled the responsibilities specified in your job description?; (2) performed the tasks that are expected as part of your job?; (3) met the performance expectations for your job role?; (4) adequately completed your required work tasks?

Extra-role. How often have you $(1=$ 'never' to 5 = 'very often'): (5) volunteered to do things that are not required in order to help your workgroup?; (6) made innovative suggestions to help improve your work setting?; (7) volunteered to help others when they have heavy workloads?; (8) lent a helping hand to others at work?

Compliance. How often have you $(1=$ 'never' to 5 = 'very often'): (9) complied with work-related rules and regulations?; (10) followed the policies established by your supervisor?; (11) carefully tried to carry out the instructions of your supervisor?

Deference. How often have you $(1=$ 'never' to 5 = 'very often'): (12) willingly followed your project organization's policies?; (13) done what your supervisor expected of you, even when not important?; (14) willingly accepted the decisions made by your supervisor?

\section{Independent variables}

Integrative interactions. To what extent do you agree or disagree with the following statements ( 1 = 'strongly disagree' to $5=$ 'strongly agree'): (15) We keep in touch with each other as a workgroup; (16) We keep in regular contact with each other; (17) We meet frequently to talk both formally and informally; (18) We interact frequently. 
900 'strongly disagree' to 5 = 'strongly agree'): (19) Our ability to function cooperatively is respected by

901 the leadership; (20) Cooperation is encouraged here; (21) Leadership in this workgroup can best be

902 described as supportive; (22) Assistance in joint-working is readily available; (23) Members feel

903 encouraged to express their opinions and ideas; (24) Leaders here encourage and support workgroup members' development

Common goals. To what extent do you agree or disagree with the following statements $(1=$ 'strongly disagree' to 5 = 'strongly agree'): (25) I am very clear about what my workgroup's objectives are; (26) I think that my workgroup's objectives are very useful and appropriate; (27) I very much agree with my workgroup's objectives; (28) I think that other workgroup members agree with these objectives; (29) I think that my workgroup's objectives are clearly understood by all; (30) I think that my workgroup's objectives can actually be achieved Equal status. Study 1 - To what extent do you agree or disagree with the following statements

912 (1 = 'strongly disagree' to 5 = 'strongly agree'): (31) We have a "we are in it together" attitude; (32)

913 People feel understood and accepted by each other; (33) Everyone's view is listened to even if it is in

914 the minority. Study $2-$ To what extent do you agree or disagree ( 1 = 'strongly disagree' to $5=$ 'strongly

915 agree') that colleagues in your proximal workgroup: (31) respect the work you do; (32) respect your 916 ideas; (33) value what you contribute at work; (34) value you as a member of your workgroup. 
Table 1. Construct Reliabilities, Construct Correlations, and Variance Extracted Estimates for Study 1

\begin{tabular}{lcccccccccc}
\hline \multicolumn{1}{c}{ Construct } & CR & 1 & 2 & 3 & 4 & 5 & 6 & 7 & 8 & 9 \\
\hline 1. Compliance & 0.92 & 0.69 & & & & & & & & \\
2. In-role & 0.94 & $0.32^{\mathrm{c}}$ & 0.62 & & & & & & \\
3. Extra-role & 0.87 & $0.29^{\mathrm{c}}$ & $0.47^{\mathrm{c}}$ & 0.53 & & & & & & \\
4. Deference & 0.83 & $0.73^{\mathrm{c}}$ & $0.30^{\mathrm{c}}$ & $0.24^{\mathrm{c}}$ & 0.55 & & & & & \\
5. Teamwork climate & 0.92 & $0.47^{\mathrm{c}}$ & $0.40^{\mathrm{c}}$ & $0.45^{\mathrm{c}}$ & $0.41^{\mathrm{c}}$ & 0.57 & & & & \\
6. Ethnicity & 1.00 & 0.04 & 0.02 & $0.26^{\mathrm{c}}$ & 0.02 & 0.09 & 1.00 & & & \\
7. Age & 1.00 & 0.09 & 0.08 & 0.07 & 0.08 & $0.20^{\mathrm{c}}$ & $0.18^{\mathrm{c}}$ & 1.00 & & \\
8. Gender & 1.00 & 0.06 & -0.03 & 0.04 & 0.01 & -0.03 & -0.08 & -0.09 & 1.00 & \\
9. Education & 1.00 & $0.11^{\mathrm{a}}$ & 0.08 & 0.09 & 0.11 & 0.01 & -0.08 & -0.03 & $0.11^{\mathrm{a}}$ & 1.00 \\
\hline
\end{tabular}

Note. $N=381 . \mathrm{CR}$, Construct Reliability. Entries below the diagonal are correlations among constructs. Diagonal entries are average variance extracted (AVE) estimates. Ethnicity. Age, gender and education were dummy-coded to test the effects of being Caucasian (Other ethnicity $=0)$, older $(\leq 50$ years $=0)$, female (male $=0)$, and postbachelor's qualification holder (bachelor's degree or below $=0$ ).

${ }^{\mathrm{a}} p<0.05$

${ }^{\mathrm{b}} p<0.01$

c $p<0.001$ 
Table 2. Construct Reliabilities, Construct Correlations, and Variance Extracted Estimates for Study 2

\begin{tabular}{lcccccccccc}
\hline \multicolumn{1}{c}{ Construct } & CR & 1 & 2 & 3 & 4 & 5 & 6 & 7 & 8 & 9 \\
\hline 1. Compliance & 0.95 & 0.72 & & & & & & & & \\
2. In-role & 0.95 & $0.40^{\mathrm{c}}$ & 0.67 & & & & & & & \\
3. Extra-role & 0.86 & $0.32^{\mathrm{b}}$ & $0.61^{\mathrm{c}}$ & 0.47 & & & & & & \\
4. Deference & 0.89 & $0.67^{\mathrm{c}}$ & $0.30^{\mathrm{b}}$ & $0.33^{\mathrm{b}}$ & 0.61 & & & & & \\
5. Teamwork climate & 0.94 & $0.22^{\mathrm{a}}$ & $0.35^{\mathrm{c}}$ & $0.52^{\mathrm{c}}$ & $0.22^{\mathrm{a}}$ & 0.62 & & & & \\
6. Ethnicity & 1.00 & $0.20^{\mathrm{a}}$ & 0.00 & -0.06 & $0.19^{\mathrm{a}}$ & 0.16 & 1.00 & & & \\
7. Age & 1.00 & 0.01 & 0.00 & 0.04 & -0.05 & 0.09 & -0.10 & 1.00 & & \\
8. Gender & 1.00 & 0.05 & -0.04 & -0.07 & 0.04 & 0.02 & 0.03 & $-0.19 \mathrm{a}$ & 1.00 & \\
9. Education & 1.00 & $0.19^{\mathrm{a}}$ & 0.01 & -0.01 & 0.15 & 0.07 & 0.01 & 0.04 & 0.02 & 1.00 \\
\hline
\end{tabular}

Note. $N=140 . \mathrm{CR}$, Construct Reliability. Entries below the diagonal are correlations among constructs. Diagonal entries are variance extracted (VE) estimates. Ethnicity. Age, gender and education were dummy-coded to test the effects of being Chinese (Other ethnicity $=0)$, older $(\leq 40$ years $=0$ ), female $($ male $=0)$, and a postbachelor's qualification holder (bachelor's degree or below $=$ $0)$.

${ }^{\mathrm{a}} p<0.05$

${ }^{\mathrm{b}} p<0.01$

${ }^{c} p \leq 0.001$ 
Causes/Dominant Conditions Change/ Integratio

Mediators

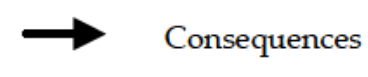

Differentiation Complexity

Uncertainty Interdependence

Fragmentation

Competition
Zero-sum
Adversarialism
Short-termism
No innovation

Environmental context

Industry custom

Law

Social influence

\section{Previous experience \\ Affective priming Cognitive priming}

\section{Partnering}

Workshops, champions' meetings

Charters, alliance agreements

Team incentives

Issue resolution/ escalation procedures

Periodic performance assessment

Training on problemsolving \& joint decision-making, e.g. resource dilemma games
Cognitive/ affective effects

Perceived group homogeneity

Perceived similarity to self

Trust

Re-categorization ('I/them' to ' $\mathrm{Us}^{\prime}$ )

Positive affect

Empathetic concern Favorable evaluations

Behavioral effects Cooperation Helping Individualizing behaviors

Productivity individual group

Improved performance Cost, quality, schedule Innovation 


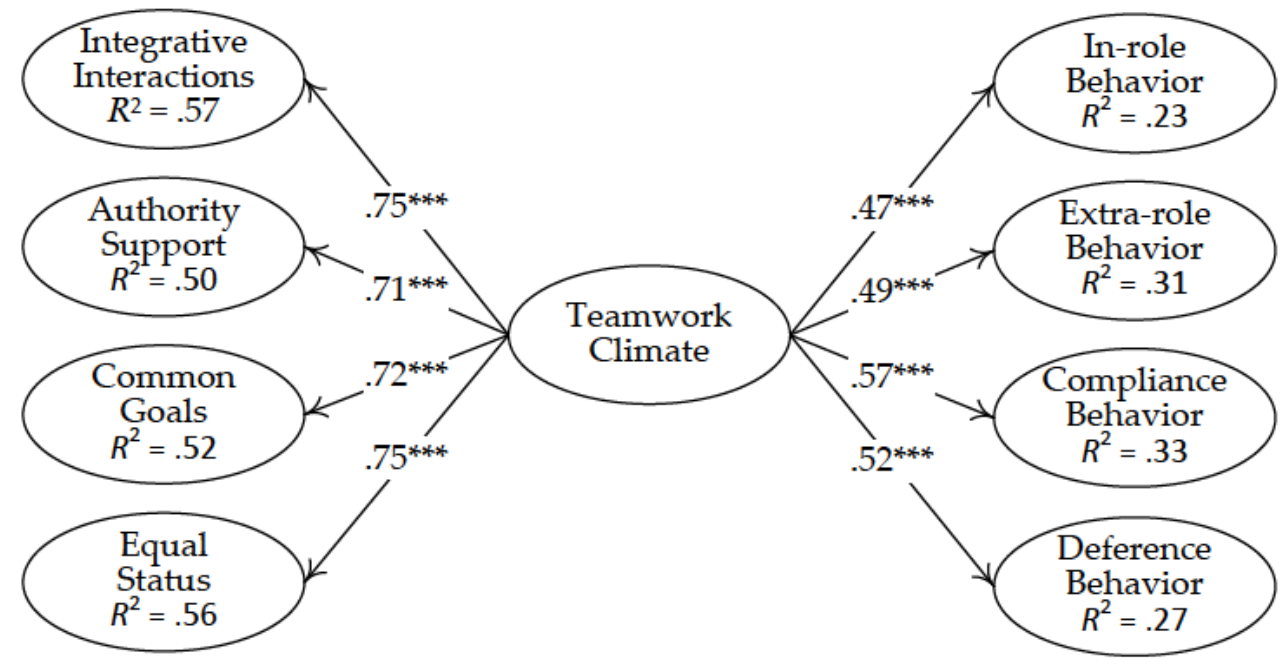




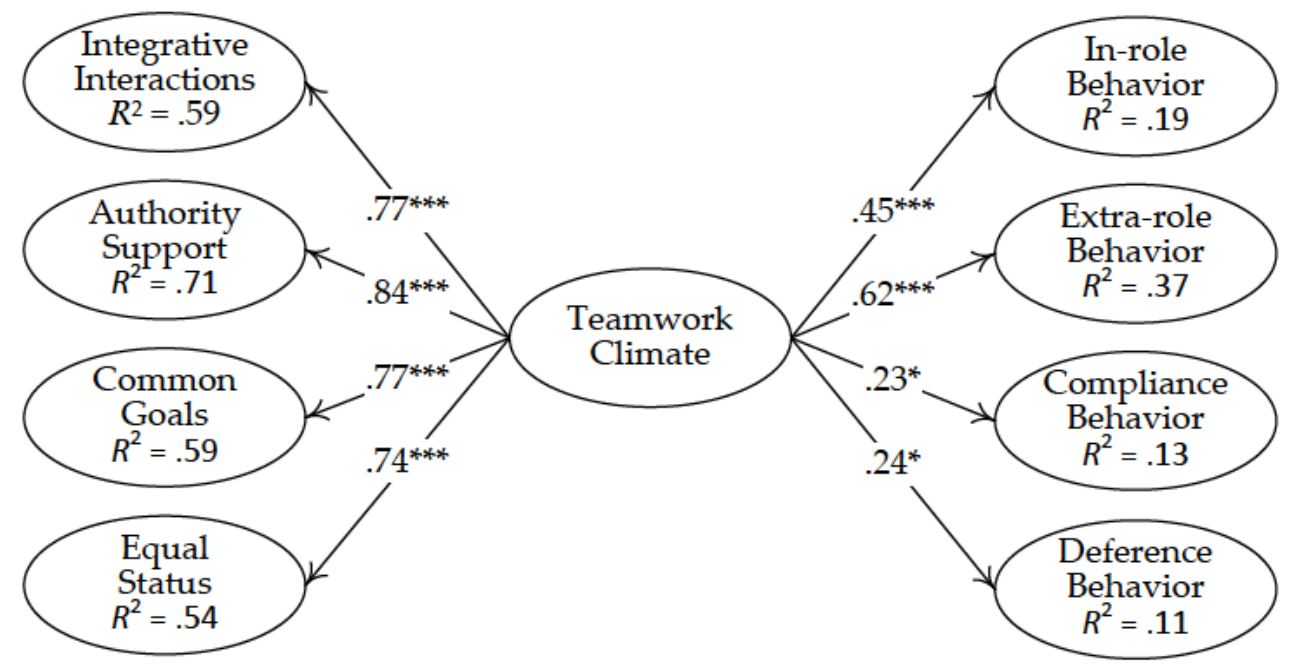




\section{Figure Captions}

Fig. 1. Conceptual model of partnering

Fig. 2. Structural equation modeling results for Study 1

$\chi^{2}(d f=599, N=381)=1286.05$ and $\chi^{2} / d f=2.15, p=.000 ;$ IFI = .91; CFI = .91; RMSEA = .06. Analyses included dummy-coded controls for the effects of ethnicity (Non-Caucasian $=0)$, age $(\leq 50$ years $=0$ ), gender $($ male $=0)$ and educational attainment $(\leq$ bachelor's degree $=0)$ on in-role, extra-role, compliance, and deference behavior. Only the effect of ethnicity on extra-role behavior was significant $(\beta=.23, p=.000) .{ }^{* * *} p<.000$

Fig. 3. Structural equation modeling results for Study 2 $\chi^{2}(d f=634, N=140)=970.42$ and $\chi^{2} / d f=1.53, p=.000 ;$ IFI $=.90 ;$ CFI $=.90 ;$ RMSEA $=.06$. Analyses included dummy-coded controls for the effects of ethnicity (Non-Chinese $=0)$, age $(\leq 40$ years $=0)$, gender $($ male $=0)$ and education $(\leq$ bachelor's degree $=0)$ on in-role, extra-role, compliance, and deference behavior. Only the effect of education on compliance behaviour was significant $(\beta=.17, p=$ $.037){ }^{* * *} p<.000{ }^{*} p<.05$ 